\title{
Open and Closed R\&D Processes: Internal Versus External Knowledge
}

By

Mohammed Saleh Al.Ansari

\begin{abstract}
:
In an attempt to help keep up with the ever changing business environments, firms are continuously attempting to find ways to open up their organizations boundaries, enabling external sources to be used. Through a means of restructuring their R\&D systems, firms will face challenges when it comes to balancing their external and internal $\mathrm{R} \& \mathrm{D}$ activities, allowing them to profit from the amount of external knowledge that they retrieve. Throughout this paper, discussions on the influences that R\&D configuration has on the performance of firms and moderating R\&D capacity will be discussed further.

According to researched findings, firms that continue to rely on external R\&D actions experience an increase in innovative performance, up to a certain point. Larger shares of external R\&D services will reduce a firm's performance. Finding the perfect medium ground is something that all chemical engineering firms will need to work on, in order to increase innovative performance, but not ruin their performance in the same respects. This paper will provide an increased amount of understanding in regards to the open innovation paradigm, which suggests that opportunity costs open for R\&D borders is a lot higher for firms that possess high quality technologically based knowledge stock (Elsevier B.V., 2012).
\end{abstract}

Key words: chemical engineering, $\mathrm{R} \& \mathrm{D}$, innovation, performance

\section{Introduction:}

Throughout history, chemical engineering firms have relied on knowledge that was pulled from external sources in regards to R\&D processes, enabling them to develop and profit from their innovations (Calantone and Stanko, 2007). The conventional approach of keeping the core of organizational R\&D activities inhouse is starting to become less critical, recent innovation models suggest that firms should open up the $\mathrm{R} \& \mathrm{D}$ boarders within their organizations, enabling tapping into external knowledgeable sources to occur (Chesbrough,2003). By tapping into these external technology sources, a large quantity of the challenges that firms face in regards to short product life cycles, product renewal periods, and increases in R\&D costs will subside (Rigby and Zook, 2002). However, on the adverse side of tapping into these external sources, having to search for new

\footnotetext{
${ }^{1}$ Department of Chemical Engineering, College of Engineering, University of Bahrain
} PO box 32038, Sukhair Campus, Kingdom of BahrainTel: +973-3944-1110 
collaborators, do require out of pocket investments in both money and time. Because of this, the higher costs of transactions may cause firms to lose sight of the benefits that engaging in external $\mathrm{R} \& \mathrm{D}$ processes has. As firms are beginning to open up the R\&D boarders, they will eventually be able to fine-tune and adapt their R\&D configurations, external and internal processes, and build new relationships or reinforce existing relations with a diverse group of partners. Because $R \& D$ processes are crucial in chemical engineering firms and the way that $\mathrm{R} \& \mathrm{D}$ processes work, managers have a difficult job of finding the perfect balance amongst external and internal $R \& D$ processes that allow them to fully capture the benefits of outsourced technology sources.

The primary focus of this paper is to investigate how tradeoffs that occur amongst external and internal $R \& D$ processes can influence a firms $R \& D$ processes and innovative performance. In particular, a great deal of focus is geared towards a chemical engineering firms internal $R \& D$ capacities-internal $R \& D$ investments that are made in building knowledge of stocks-moderating the relationships between the R\&D structure of a firm and the firms innovative performance. Research has revealed that a firm can efficiently tap into external knowledge sources by investing in R\&D. Firms that choose to invest in internal R\&D stock building activities will be able to evaluate and recognize external sources that they can integrate and use with their corresponding knowledge that they encompass (Cohen and Levinthal, 1990). Firms engaging in this practice will rely on fewer linkages that possess value, to help achieve increased innovative output (Arora and Gambardella, 1994). Because assimilation and selection of external knowledge sources depends on the amount of knowledge that a firm possesses, (Cohen and Levinthal, 1990), it is important to know how internal R\&D capacities can influence the relationships between the degrees of $R \& D$ outsourcing and innovative performance.

Through investigating the moderating roles of $\mathrm{R} \& \mathrm{D}$ capacities, in regards to balancing external and internal $R \& D$ processes, this paper evaluates conditions that open innovation paradigm agreements for increased innovative performance should be attended to. By doing this, contributions to literature can occur in two different ways. The initial way is to build on studies that were performed by Cassiman and Veugelers (2006), in regards to testing the extent that external and internal $\mathrm{R} \& \mathrm{D}$ processes substitute or complement increased innovative performance. Cassiman and Veugelers (2006) investigate how every distinctive $\mathrm{R} \& \mathrm{D}$ structure will influence innovative performance, focusing on the varying degrees of $\mathrm{R} \& \mathrm{D}$ outsourcing. Through the typology approach established by Cassiman and Veugelers, this paper is intended to provide an increased understanding of the drawbacks and benefits that coincide with opening a firms $R \& D$ boarders and performing tradeoffs through external and internal $R \& D$ processes. Second, research emphasizes the moderating role that internal R\&D 
investments play, in regards to capturing external knowledge flows that are unintentional (Escribano et al, 2009) allowing achievement of increased innovative outputs, but taking the firms R\&D capacity influences into account, as well as the knowledge flow that occurs during external $R \& D$ processes. By evaluating the moderating roles of R\&D capacities within context, this paper will provide a new insight on chemical engineering firm's abilities to capture value through balancing their external and internal R\&D processes. Furthermore, it provides a variable in context that allows a better assessment of complementarity versus substation dichotomies.

To elaborate on these issues, this paper will investigate the external and internal R\&D configurations of intensive manufacturing firms. Firms that possess an external and internal R\&D system experience increased innovative performance. However, firms that choose to carry out more external processes than internal processes discover that $R \& D$ activities can worsen. $R \& D$ capacities significantly moderate curvilinear relationships. Firms that possess greater R\&D capacities benefit more from the external R\&D processes in regards to innovative output. They are able to accomplish this feat by using a small share of external R\&D processes, in comparison to firms that have lower $\mathrm{R} \& \mathrm{D}$ capacities. The finding provides a better understanding in the relationships between external and internal R\&D, which goes beyond classic oppositions amongst complementarity and substitutions. The implications state that external and internal R\&D processes are considered to be complementary, until they reach a certain point, where they turn into substitutions. The substitution effect occurs a lot more within firms that have greater R\&D capacities. The results provide an increased understanding of open paradigms for innovation which state that opportunity costs for opening up a firms R\&D boarders are increased for firms that possess an increased amount of internal R\&D capacities.

\section{Transitioning from a closed R\&D system to an open process}

In an attempt to cope with competitive environments, firms choose to consistently invest in creating various technological capabilities and innovative activities. Focusing all of the firms attention on the development of internal R\&D processes and capabilities is no longer seen as a sufficient way to cope with shortening the life cycle of products and increasing costs, as well as increased complexities of technologies. Because of these drivers, organizations have been forced to go through mutations, where the structuring of closed internal $R \& D$ processes are fading rapidly and shifting towards in-house $R \& D$ structures to open R\&D structures that tap into external knowledge sources through building alliances, licensing and technological agreements (Hagedoorn,1993). In an 
illustration done by Whittington (1990), ratios of internal R\&D processes versus external R\&D process expenditures have doubled between the years of 1967 and 1986, however, R\&D partnerships have grown tenfold over the past three consecutive decades (Hagedoorn, 2002).

Earlier depicted models of innovation showed a process that was done in an internally controlled environment. The chemical engineering firm was the location were all innovation along with the innovative process was done, this process was kept secret away from the prying eyes of competitors and other players that could benefit from the information and knowledge that the internal firm possessed.

When the innovations left the R\&D lab, the successful innovations possessed enough caliber to finance any other subsequent $\mathrm{R} \& \mathrm{D}$ activities that needed to be carried out in-house. Since the activities were considered to be specific to the existing firm, the need to share the information with other firms for cost purposes was not required (Chandler and Hikino, 1990). This innovative model was not an efficient method, as Nelson (1959) noted earlier on, this method did not prevent information from leaking outside of the firm. Firms would openly fund R\&D projects that were commercialized and appropriated elsewhere.

Instead of taking a closed innovation approach, recent models suggest that an open paradigm in regards to innovation should be attempted; this allows R\&D structures to be seen as open systems (Chesbrough, 2003). According to this paradigm, firms should be able to use ideas that they obtain from external sources, along with their individual internal knowledge, external and internal market plans, to assist with advancing technologies (Chesbrough, 2003). Firms no longer exclusively rely on their in-house or internal innovative ideas, but instead combine internal knowledge along with external knowledge equally. Open $R \& D$ systems allow firms to outsource $R \& D$ technologies and projects with no clearly defined plans to market them. By exposing the ideas to outsourced partners, the $R \& D$ projects can eventually find their way on the forefronts in the market. This allows a firm to in-source any external ideas, by integrating suppliers, knowledge sources obtain externally, and customers to help increase the innovativeness of a firm. But, according to Chesbrough and Teece (1996), being open in this manner will imply an engagement with outsourced sources, but not equate to a complete reliance on them. A firm that depends on their external partners entirely will lack internally based R\&D processes, and the ability to be able to fully capture and utilize the external knowledge that is being given to them. This does not evaluate the explicit role that $\mathrm{R} \& \mathrm{D}$ capacity has in regards to balancing external and internal $R \& D$ processes for increased innovative outputs. The primary focus of this paper is to thoroughly investigate the role. 


\section{The impact of external and internal $R \& D$ processes on innovative performance}

There are plethora's of theories that evaluate the shift from closed $R \& D$ processes to open innovative models, as well as the increasing reliance of R\&D activities that are performed externally.

According to the TCE, also known by its non-acronym term of transaction cost of economics, organizations involved in economic activities are driven by two factors, minimizing production as well as minimizing transaction costs. Considering this perspective, the influx of R\&D labs during the latter 1940s can be attributed to lowering costs of managing and organizing innovative in-house projects, rather than solely relying on the markets (Mowery and Rosenburg, 1989). Progressively, as the costs that are directly associated with $\mathrm{R} \& \mathrm{D}$ processes continues to increase, firms have found different ways to minimize some of these costs by sharing the cost with outside firms (Katz, 1986). Firms are also beginning to realize that there are some $R \& D$ processes that are not considered to be technological areas that are specific to the firm, therefore, they have the option of choosing to engage in a joint $\mathrm{R} \& \mathrm{D}$ activity, or outsourcing some of the activities to other firms, due to the cost effectiveness and innovative outputs (Hagedoorn, 2002).

Instead of putting all of the focus on cost saving methods, there are other types of theories that focus on how knowledge is shared amongst firms, in an attempt to achieve better innovative performance (Dyer and Singh, 1998). Because technology is constantly changing, the base of knowledge that firms possess suggest that they broaden their horizons and existing knowledge base that they have of technologically sound practices to integrate different knowledge areas into the internal R\&D processes and external technological outsourcing tasks (Kogut and Zander, 1992). Because new developments within non-core technologies occur at an alarmingly fast rate, firms will have a limited amount of time to be able to carefully and selectively manage and screen technological in-house knowledge. Arguably, relational views of firm perspectives argue that technology outsourcing and inter-firm knowledge links will enable a firm to keep their novel developments up to date, therefore increasing the learning gains that are achieved within the corporation. Firm's technological capabilities will increase their chances of developing and realizing innovative product ideas (Becker and Dietz, 2004). Aside from this basic principle, two other things that can affect a firms innovative performance is their ability to trust in their long-term relations which will help them reach greater performance (Zaheer , 1998). Aside from the basic ROI, an acronym that means return on investment, scholars have noticed that linkages between firms affect the innovative performance of a firm (Shan et al, 1994). 
Additional research suggests that a firm does not have to possess in-house capabilities or knowledge, they only need to worry about being able to gain access to these two valuable components (Barney, 1991). By outsourcing technology, firms will be given the opportunity that they need to be able to strengthen their capabilities and their knowledge. External technological sources are extremely beneficial to firms, provided these external sources provide an immense amount of knowledge and are able to exploit the external resources that are being offered (Mitchell and Singh, 1996), exploitation of these resources will enhance the performance of a firm in regards to the variety of products they are able to introduce and the time that it takes to get these products to market (Eisenhardt and Schoonhoven, 1996).

However, despite the benefits that exist with inter-firm relations, there are also organizational challenges that exist with external R\&D activities. Looking at everything from a TCE perspective, the costs that are associated with searching as well as choosing a $\mathrm{R} \& \mathrm{D}$ partner is expected to rise, forcing additional resources to be required for the allocation of these partners. Also, the shift that is in place from a closed to open innovative systems is going to increase transactional costs, because they require increased effort to be able to manage, coordinate as well as control the R\&D actions that partners will be involved in (Gulati and Singh, 1998). Because of the differences that exist amongst the focal firms and their $\mathrm{R} \& \mathrm{D}$ partners in regards to control systems and information, the costs for coordination are more than likely going to rise as well (Dyer and Singh, 1998). As firms continue to move towards the open $\mathrm{R} \& \mathrm{D}$ system, the internal $\mathrm{R} \& \mathrm{D}$ structures will require some type of fundamental transformation to occur, because the roles will ultimately switch from discovery generation tasks to systems and activity design (Chesborough, 2005). The changes that will occur within organizations will require increased costs, but the benefits of open $\mathrm{R} \& \mathrm{D}$ systems may only be seen as a long term goal. Scholars warn firms about engaging in external R\&D activities when the amount of knowledge flow taken from external sources begins to slow down, by engaging in a learning-by-doing type arrangement, the dependent stock firms will be impeded (Bettis et al., 1992).

Regardless of the theoretical explanations that exist, empirical evidence in regards to the effect of an R\&D configuration on a firms performance is fairly limited. One of the initial studies that was performed by Arora and Gambardella (1994), states that collaborations that took place within the biotechnological industry showed that firms who possess strong internal technology knowledge were able to utilize external innovative information effectively in comparison to firms that lacked the knowledge necessary for the implementation. Firms that possess a make and buy type strategy are more than likely going to profit from their innovations, while forms that choose to not follow the make only or buy only strategies will experience increased innovative performance (Cassiman and 
Veuglers (2006). There are other studies that argue against this point and lean more towards the substitution effect. External and internal R\&D processes are substitutions for firms that engage in low technologically based industries (Audretsch et al., 1996). Lauren and Salter (2006), discovered that negative effects exist for firms that search heavily for external knowledge sources.

Even though both of these theories seem to contradict each other, they do agree on one point. They suggest that by having a firm open up their R\&D system that benefits exist for the innovative activities conducted by the firm. By relying heavily upon external technological sourcing, an increase in coordinating, searching and monitoring costs can place a hindrance on building path-based knowledge for stocks within the firm.

\section{Technology and science studies: explore external knowledge bases}

STS, an acronym used to emphasize Science and Technology Studies is one of the leading research fields that have emerged over the past five decades. The contributions made in this particular area of study have impacted various research fields. Together, these studies reveal a varying amount of developments in phases of STS with divergence and convergence within the field, including the quantitative study of technology and science from the main body of STS.

Emerging research fields within the natural sciences and social sciences originate along the interstices of other well-formed disciplines when a researcher from a neighboring discipline with different disciplinary perspectives shares common interests. Through working together, researchers are able to develop shared concepts, analytical frameworks and methodological methods. This will allow the researchers to move into publishing their findings into journals that fall underneath the "parent" discipline, establishing their own journals, specialized university departments, and professional associations. Eventually, some of these fields will have enough characteristics to be able to develop a newly achieved disciplinary stature.

These convergence practices are seen throughout the Innovation Studies fields. However, one thing that many are unaware of is that convergence is not the only outcome. The Science and Technology Studies field possesses two different types of elements. STS possesses a divergence and convergence element, since it initially emerged as a specialty during the 1960s.

From a science perspective, divergence and convergence have negative and positive consequences that they possess. The assumptions that are shared by the discipline will increase the speed and coherence that is distributed through problem solving (Turro, 1986). However, it can also lead to intellectual breeding or group thinking (Rafols et al, 2012). A discipline will allow a researcher to 
refrain from having to constantly justify judgments and assumptions in regards to standards of research quality, they enable standardization, while also generating scales that are required to correctly justify high investments that are done on a fixed-cost scale in regards to data collection, career development, and instrumentation. However, these same disciplinary powers can also blind researchers from other alternative perspectives that may or may not exist; cognitive infrastructures can be flawed, embedding trajectories that are pathdependent and difficult to escape from.

The process involved with moving from research fields of shared interest to disciplinary statures are punctuated by publications of series that are connected contributions acting as models, or paradigm cases that are replicated or borrowed from (Turro, 1986). The hierarchy that exists between implicit and explicit shared assumptions that core contributions modify and establish, the structure for theoretical debates that continue to be ongoing (Nightingale, 2008). Evaluations that have been performed on the "theory of firm" suggests that groups of researchers need to be able to agree on specific fundamental assumptions before disagreements on certain minor points are reviewed over, by exercising this practice, fundamental assumptions are less likely to occur.

STS has made a lot of core contributions throughout the past fifty years, understanding and mapping out these developments will help a better understanding of the field be further developed. The only way that a better understanding can be accomplished is through quantitative and qualitative analysis of chapters that can be located within the STS handbooks. Obtaining information in this manner is valuable in many different ways. First, STS is an interesting topic within its own right, not only for Innovation Study scholars that are searching for specific insights into developing their own fields.

Also, the analysis possesses implications for better understanding the processes that academic fields and other types of disciplines emerge. This occurs when having common interests and being able to recognize the advancements of these common interests through various shared methods, journals and conferences, and then the interested being recognized by the rest of the world, formulates the change. Interconnected hierarchies of assumptions help structure the development of a research field, but they do not exist within cognitive isolation. Researchers embed their physical artifacts, work and other social structuresacademically composed papers help with communication and memory, for instance, conferences assist with building collective identifiers. The amount of research required is greatly dependent upon high fixes invisible infrastructures that will need to be maintained and built (Nightingale, 2008). An institution builder will play an important role in integrating and creating the elements within the infrastructure, when it fails, or when mismatches between elements are large, they may falter. 
Internal divergence observed provides methodological warnings in regards to bibliometric analysis of this caliber. They suggest that certain academic fields, such as biological species, do not possess an inner "core" that are drawn on as time passes. This implication in regards to choice has produced a different scale of analysis, resulting in convergence studies of Innovation Studies and Entrepreneurship emulating divergence from common cores instead of analyzing them from higher levels of aggregation (Bhupatiraju, 2012). The divergence from common origins that are observed in respects to qualitative and quantitative studies of STS might emulate internal convergence when viewed at lower levels. The features make academic fields of history sensitive to any outside bias, specifically internal actors that construct past events selectively to justify future or current allocations in regards to power and resources. Methods used outside of STS may be perceived as a critical friend, will go part way in actively addressing some instances of biases, it is specifically appropriate that sociological sensitivity in regards to construction, reflexivity in narratives and numbers has relevance to the past of STS.

\section{Contributions of STS}

The STS field, just like those of Entrepreneurship and Innovation Studies is now between four to five decades in age. What this means is that there are only a select amount of researchers that are around today that were initially around when the field began to emerge during the 1960s. With the initial memories regarding this field beginning to fade into the distance, it is time to develop an extensive overview of the main contributions that occurred within the field during its period of emergence. The best way to do this, is instead of relying upon subjective approaches as analyzed in previous reviews, adopting quantitative approaches that are based on evaluations taken from handbooks transcribed by the authors of various chapters as being the core contributions within the development of the STS field.

The methodology of the STS practice has been able to identify 155 core contributions to STS as authors perceived in authoritative handbooks. These handbooks constitute that there is a mutual consensus as to what the most vital contributions in the field are, who the influential authors are, and what institutions have played vital roles in developing the field. By evaluating the contributions made by these authors, an understanding of how the field eventually began to evolve can be reached through approaches that have emerged throughout the times.

Establishing a new field is never an easy task. The pioneers that are responsible for the establishment of the new field are likely to face an immense amount of 
resistance upon the introduction of the newfound ideas. These pioneers do not have a source of funds that is backing their research. They do not have a community of collaborators that is willing to stand behind the information that they discover. In a means to overcome all of the challenges, the individuals will need to be willing to exploit the opportunities that exist (Fagerberg et al., 2011). These individuals must be willing to behave as innovators, in regards to making intellectual contributions and constructing analytical frameworks and concepts.

\section{Technology Sourcing}

By definition, technology sourcing is a specific method that a firm acquires in which $\mathrm{R} \& \mathrm{D}$ technologies undergo in-house or internal research and development processes, as well as external technology processes, that can be carried out by customers, suppliers, or consumers (Belderbos et al, 2004). Internal Development of Technology

The term Internal Development of Technology is used widely to define R\&D activities that firms undertake for in-house technological developments, processes that will help ensure that the firm gains control over distribution and maintaining viable technical capabilities for the firm (Pisano, 1990). Even though a larger portion of the internal technological development is obtained through the knowledge that individuals within the firm readily possess, tacit knowledge, which is obtained through learning by doing is seen to be the most competitive and valuable resource that a firm can have in terms of developing products for markets (Hitt et al., 2001). Because tacit knowledge is something that is embedded into unmodified routines and not easily transferred, this knowledge can serve as a secret that the firm can keep from their competitors (Leibskind, 1996). Tacit knowledge is difficult to imitate as a result and is unique in its own right, possessing higher probabilities of creating strategic values as opposed to simple articulable knowledge (Lane and Lubatkin, 1998).

In regards to conducting complex projects that require research and developing new products, internal technological developments are likely to meet the objective, because internal tacit skills and knowledge satisfy the demands for information exchange and interaction among multiple functions within the firms (Mowery and Rosenberg, 1989). These types of information exchanges are easily transferred within the internal workings of a firm, not only because the forms possess an increased amount of internal knowledge, in regards to the technical details of their products and the production processes that they go through, but also because the firms are hesitant to provide information on the core source of technologies utilized with outside contractors who may revert to utilizing their research projects and technologies and sharing them amongst other firms involved in the same type of work. Based on the points expressed in the above 
arguments, it is expected that positive relationships existing amongst internal technological development and new product development from an internal perspective will creative positive relationships within firms.

\section{External Development of Technology}

Over the last few decades, firms have actively been making use of external sources and complementary resources, because single firms are finding it difficult to possess enough information to keep their competitive advantage above their competition, while still being able to create products that allow them to extend their competitive advantage (Harrison et al., 2001). There are a lot of innovative firms that have transitioned to an open innovative model, choosing to utilize external actors and other sources to assist them with maintaining their ability to sustain innovations for the market (Chesbrough, 2003). New product development firms are finding it difficult to produce new products, without seeking simultaneous help amongst all fronts of technological advances from external sources (Thorgren et al., 2009). The utilization of external resources to help maintain market competitiveness is well documented in various literary pieces (Chatterji, 1996).

Customer and supplier relationships play an important role in the transfer of knowledge (Takeishi, 2001). Also, ties amongst competitors, industry members, provide helpful exchanges of knowledge that are in direct relation to effective methods that improve the production of innovative products (Luo, 2007). Even outsourced supportive institutions, such as law firms and accounting firms, and higher learning institutions provide invaluable knowledge that a firm can utilize for their new product developments. External technological sourcing is built on the grounds to help obtain required knowledge to catapult the success of new product innovations (Hislop, 2002).

\section{The relationship between high quality management and innovation}

For the past thirty years, innovation has been brought to the attention of practitioners and researchers (Gatignon et al., 2002). In a topsy-turvy economy, innovation is a driving force for seizing newfound opportunities and protecting knowledgeable assets (Teece, 2000). Innovation plays a vital role in regards to providing unique items and services through creating increased value from previously recognizable products and services and establishing barriers that are ample for entry into the market (Llorens Montes et al., 2005). Innovation has motivated researchers to be able to correctly identify driving forces behind innovative products. There are some researchers that pay their dues to quality management when it comes to the development of new products and/or services. Quality management, also commonly referred to by its acronym term QM 
contributes to financial and operational performance, this will allow a firm to obtain the competitive advantage that they require over competitors (Kaynak, 2003).

Studies have been conducted on the relationship between quality management and innovation since the early 200s. While there have been multiple studies conducted on the ties between quality management and innovation, most of these studies had a few shortcomings that emerged shortly after the literature had been thoroughly reviewed and analyzed. A lot of earlier studies failed to correctly explain the specific QM practices that are either indirectly or directly associated with innovative performance. The studies simply pointed out direct relations that existed between the two principles.

Prior studies had various limitations that were set upon them during the research stage. Researchers were limited to the amount of innovations that they were able to assess. There were some studies that only examined a single innovative performance type, which did not leave much room for evaluations and proper analysis to be done (Abruhosa, 2008). Evaluations of prior research that was conducted on the correlation between the two practices caused a multitude of questions to surface. The two main questions that surfaced were in regards to if it were worthwhile to examine quality management practices that in turn lead to process and product innovations. Another question that arose from the studies that were previously conducted is in regards to the types of innovations that should be analyzed within the studies.

The studies that were previously conducted devoted limited amounts of time to examining all of the different types of innovative processes that exist. With this narrowed view of innovative processes, barriers of misunderstandings began to arise in regards to how quality management benefited the innovative process. All of the dimensions of the innovative process will need to be examined in order for clearer understandings of the effects of quality management have on innovative processes.

\section{What Are QM Practices?}

The acronym term QM, which drawn out equates to quality management is a holistic philosophy of management that combines all of the organization through continuing striving to improve organizational changes that be underway (Kaynak and Hartley, 2005). Quality management captures features that are taken from distinct organizational models, extending these features through methodologies, principles, and specific techniques that are focal to the firm (Spencer, 1994). Researchers convey that it is vital that firms define as well as develop their QM practices, this way they can be assisted through what has come to be known as a multi-dimensional managerial approach. The term QM practice is used to describe specific and vital activities that individuals require that are expected to directly or 
through indirect channels lead others to ensure improved performance as well as a competitive advantage (Flynn et al., 1995).

There has been a lot of attention given during research periods to constructing QM as well as examining the link between the practices performed by QM and the output performance of others. Most of the research that has been done on QM practices and how they relate to performance has been performed through interdependent evaluations of specific firms. Researchers will review organizations to be within systems of interlocked processes. This so-called linkage research tests the associations amongst QM practices (Sila and Ebrahimpour, 2005).

\section{Classiffing Innovation}

The term innovation is used to describe new ideas, knowledge applications, methods, and skills that will produce unique leverages and capabilities within an organization, to give it the extra push that it requires to maintain competitiveness within the marketplace (Andersson et al., 2008). This definition, although somewhat closed, reflects upon a broader view of what innovative processes are by conveying that there are two different types of innovative processes that can be classified as administrative or through technological advancements. In the open global markets that are currently in place within the present economic system, firms should be able to identify any new chances that exist within the market to shield as well as reconfigure technologies, knowledgeable assets, competences, and assets, ensuring that they maintain a competitive advantage (Teece, 2000).

It is vital that firms understand the different types of innovative processes and how each process will possess its own distinct characteristics, specific types of innovative processes will require organizations to display sophisticated and unique responses. Researchers have been able to correctly explore innovative processes in a variety of manners. Even though previous research has been able to convey different classifications that innovations can be placed into, there are actually five primary innovative process types. These five types include: incremental processes, incremental products, radical processes, radical products, and administrative processes (Chandy and Tellis, 1998). Arguments investigating the different innovative process types can help a practitioner break down the strategy of innovation into a specific innovation area. This allows resources to be allocated correctly. To be able to correctly understand the five primary types of innovative processes that exist and the way that these processes can correlate in conjunction with QM practices, the differences amongst the innovative practices will need to be examined further.

The first way that innovation is split is into two different categories. It can be split down the middle into administrative and technological forms of innovation. The term Administrative Innovation relates directly to the applications of applying new ideas that will directly improve organizational systems and structures, as well 
as other processes that pertain to the social structuring of the organization (Damanpour, 1987). However, technology innovation in contrast is defined as adopting new technologies that will need to be directly integrated into processes or products (Yonghong, 2005). Administrative innovative practices are triggered by needs that exist internally in regards to the structure and coordination within the organization, while technological innovation is used as a response to environmental factors, such things as the condition of a market or the technical knowledge for the new process or product (Daft, 1978). Administrative innovative processes utilize top down approaches. In this type of approach, members of higher ranking management will choose to commit their time to activities that are relevant, where technological innovative processes will commit themselves to a bottom up style. The bottom up style will involve the interactions of technicians that are classified along the lower levels of the organization (Daft, 1978). Administrative innovative processes will require an investment in costs and cannot be interrupted by the organization in any way; this innovative process will affect all of the basic working activities that customers have to go through in both a direct and indirect manner (Weerawardena, 2003).

Specialized agencies are assigned to diffuse administrative innovations (Teece, 2000). However, when it comes to property laws and technological innovations, these same consulting firms will need to be called upon for their assistance. Based on the degree of innovation, technological innovative practices can be broken down into smaller increments to include radical innovations and process innovations.

Technological innovations, which are defined of half of what innovative processes are can be further divided into radical innovation and incremental innovation, when certain features are considered: the change levels that need to be justified (minor versus major), targeted customers or targeted markets (existing versus new), as well as the risk levels (low risks versus high risks). Incremental innovations refer to minor changes that are taking place within existing tech designs, prices, functions, features, and quantities that are required to meet consumer need (Garcia and Calantone, 2002). Radical innovations are correctly defined as the adoption of new technologies that will create demands that are not presently being recognized by consumers or markets (Jansen, 2006). Incremental innovative processes put all of its focus on broadening, redefining, enhancing, and exploiting the present skills and knowledge of technical trajectories (Gatgnon, 2002). Radical innovations are geared towards concentrating on specific market pulls (Li, 2008). Incremental innovative processes will entail lower risks be taken, which will provide fewer benefits based on the low amount of risks (Koberg, 2003). Contrasting these two broken down halves of technological innovation, radical innovations will require a higher uncertainty in the turn out and come with higher levels of risk (Moguilnaia, 2005). Studies have concluded that radical 
innovative processes only equate for ten percent of new innovations, incremental innovative processes equate for ninety percent (Rothwell and Gardiner, 1988).

It is vital that firms decide upon the subject that they want to receive innovative properties when heading into new market positions. Innovation subjects are either done through processes or through products. Product innovation is defined as changing the end to provide services and products that adhere to market demands. Process innovation will define changes that are made to the methods when it comes to producing the end product or providing the end service (De Propris, 2002). When both of these innovative process subjects are evaluated, product innovative processes can be broken down into smaller incremental units of incremental product innovation and radical product innovation (Reichstein and Salter, 2006).

Radical product innovation processes are better defined as innovations that are associated with introducing new products or services that will incorporate different technologies than those that are presently being used and adopted by the general public. Incremental product innovation processes is used in reference to describe innovations that are related to introducing products and services that will directly provide different improvements, features, and benefits to the existing technological markets (Chandy and Tellis, 1998).

Process innovation refers to changes that organizations make when it comes to producing specific products or providing specific services (Utterback, 1994). Process innovation relates directly to improvements in efficiency and production activities to deliver new products (De Propris, 2002). Process innovation on the other hand, is geared more towards introducing new elements into the current production machinery, materials used, task specifications, processes, and workflow mechanics (Damanpour, 1991).

When looking at the degrees of innovation, classifying innovation into two separate categories makes sense (Reichstein and Salter, 2006). Radical process innovative processes are used to refer to innovative processes that are associated with applying the new or improved elements into the workings of an organizational body. Incremental process innovative processes are identified by innovating minor changes into the present performance, function or look of a specific product, thus allowing the organization to achieve lower costs when it comes to manufacturing the product, but be able to produce a product that is still considered to be a high quality item (Reichstein and Salter, 2006).

\section{Implications of QM}

Organizational efforts to improve and establish QM practices will relate in a positive manner to innovative processes and products in the existing markets, as 
well as in the emerging markets. QM practices that are exercised through a form of process management will affect businesses in two different ways, both directly as well as indirectly.

The capability of organizations to be able to correctly manage processes is extremely beneficial to a firm that is struggling to create incremental innovation and radical innovations in the competitive global economy. Process management activities will directly and positively relate to administrative innovative processes, radical innovative processes, and incremental innovative processes. Knowledge and information that is conveyed in a routine or otherwise set fashion will help a firm establish a learning base that is requires to be able to add value to the products or services that it offers, within the competitive markets. Flexible and simple routines are to be valuable to firms that are targeting a specific market that has yet to emerge.

Controlling and measuring performance in an appropriate manner to ensure that conflicts are coordinated in regards to critical processes will be necessary when generating and guiding radical and incremental innovations. Controls within process management will likely help firms to be able to maintain plausible and foreseeable goals, reduce the amount of time that it takes to accurately develop products, while also meeting the needs of customers within emerging and existing markets. This evidence is consistent with the evidence that has been previously recorded by Khazanchi, 2007).

Researchers have been able to point out in previous studies that the proper management of process aids in regards to facilitating problem solving in a creating fashion and achieving innovative processes. Process management activities will increase the amount of incremental learning, which will enhance the efficiency of processes and also reduce variances in performance (Benner and Tushman, 2002).

\subsection{The Moderation Role Of Appropriability Regimes}

A strategic appropriability regime stems from secrecy, lead time advantage and the complexities that come from creating new products (Nieto-Antolin, 2007). Organizations, when it comes to creating new products or services, will do everything in their power to ensure that their creative processes are not leaked to competitors, thus giving them the edge that they require to enter into the marketplace with innovative plans that no other corporation has thought of. Secrecy requires keeping industry specific information private, in regards to formulas, specific trade knowledge, and information pertaining to customers and sales strategies exercised by the organization.

Firms choose to keep a secrecy about their innovative processes to be able to gain a lead-time advantage over their competitors. Lead time advantage is defined as a specific type of advantage that a firm obtains by developing a product or service prior to their competitors coming up with the same ideas for the product or 
service. In order to be successful in the competitive global economy, organizations will need to find different ways to maintain their lead time advantage over competitors that share within the same marketable niche that they are also in.

Firms are able to obtain lead time advantage in various ways. The primary way to obtain this advantage is to innovate quicker than competing firms or organizations; this will make the firm who marketed the product or service prior to their competitors marketing get a head start on the targeted market that may require the utilization of the created product or service. To gain a better lead time advantage on competitors, firms can choose to create complex product designs that cannot easily be duplicated by other organizations that are involved in the same niche. Complexity of the products design will make it difficult for other organizations to emulate the innovative ideas that the original firm had, therefore protecting their idea from imitators. If imitators were to try to duplicate the ideas of the firm, they would end up having to devote an immense amount of time to doing so, thus increasing the amount of their investment and limiting their resources (Pavitt, 1984).

\section{Conclusion}

Because of the fast-paced innovative environment, firms are constantly turning their traditional closed $\mathrm{R} \& \mathrm{D}$ labs into open systems that enable them to tap into the sources of knowledge that external sources possess. Ensuring the R\&D system is organized is a challenge that firms will face for future innovative processes. To gain a better understanding of how a firm organizes the knowledge from their external partners, the study will further examine the influences that $\mathrm{R} \& \mathrm{D}$ configurations have on innovative performance, as well as the moderation role of the R\&D capacity of a firm.

In summary, this paper provides a better understanding of the trade-off that occurs between external and internal $R \& D$ processes in regards to a firm's innovative performance. A firm that moves the boundary of their R\&D configurations through engaging in $\mathrm{R} \& \mathrm{D}$ activities externally will need to be able to effectively balance the benefits that exist from tapping into an external source, along with the costs that are associated with coordinating, searching and monitoring the linkages. This paper provides further highlights on how focal firm's technological capabilities along with their internal amount of knowledge can influence the balance. Firms that possess high levels of R\&D capacities will be able to exploit and capture the external knowledge by means of $R \& D$ collaborations in regards to innovative outputs, through investing in external 
$\mathrm{R} \& \mathrm{D}$ processes in opposition to firms. The study provides a test of how the open $\mathrm{R} \& \mathrm{D}$ process explores which conditions will provide a greater amount of benefits in regards to $\mathrm{R} \& \mathrm{D}$ openness processes.

The study examines the role $R \& D$ configurations and $R \& D$ capacities play on firm's innovative performance, but there are some limitations that still exist. First of all, the openness practice is only being employed by a small quantity of firms, if all firms adopt this practice, there will be increased exploratory power. Also, the study puts focus on the role that external $\mathrm{R} \& \mathrm{D}$ processes go through, without emphasizing the importance of investigating the characters of the R\&D partners that firms should join with. Examining the various types of R\&D partners that exist within the local firms require some further inquiries. Additional research performed in the future should focus on the nature of the $R \& D$ collaborations, allowing a thorough evaluation of the role of $R \& D$ systems on firm's performance.

\section{References}

Calantone, R.J., Stanko, M.A., 2007. Drivers of outsourced innovation: an exploratory study. Journal of Product Innovation Management 24 (3), 230-241.

Chesbrough, H.W., 2003. Open Innovation: The New Imperative for Creating and Profiting from Technology. Harvard Business School Press, Boston, MA.

Chesbrough, H.W., Teece, D.J., 1996. When is virtual virtuous? Organizing for innovation. Harvard Business Review 74 (1), 65-73

Rigby, D., Zook, C., 2002. Open market innovation. Harvard Business Review 80 (10), $80-89$.

Arora, A., Gambardella, A., 1994. Evaluating technological information and utilizing it scientific knowledge, technological capability, and external linkages in biotechnology. Journal of Economic Behavior \& Organization 24 (1), 91-114.

Cohen, W.M., Levinthal, D.A., 1990. Absorptive-capacity - a new perspective on learning and innovation. Administrative Science Quarterly 35 (1), 128-152.

Barney, J., 1991. Firm resources and sustained competitive advantage. Journal of Management 17 (1), 99-120

Becker, W., Dietz, J., 2004. R\&D cooperation and innovation activities of firms evidence for the German manufacturing industry. Research Policy 33 (2), 209223. 